\title{
Copolymerization of epoxides with cyclic anhydrides catalyzed by dinuclear cobalt complexes
}

\author{
Yo Hiranoi and Koji Nakano*
}

\author{
Full Research Paper \\ Address: \\ Department of Organic and Polymer Materials Chemistry, Tokyo \\ University of Agriculture and Technology, 2-24-16 Naka-cho, Koganei, \\ Tokyo 184-8588, Japan \\ Email: \\ Koji Nakano* - k_nakano@cc.tuat.ac.jp \\ * Corresponding author \\ Keywords: \\ cobalt; copolymerization; cyclic anhydrides; epoxides; polyesters
}

Beilstein J. Org. Chem. 2018, 14, 2779-2788.

doi:10.3762/bjoc. 14.255

Received: 16 August 2018

Accepted: 16 October 2018

Published: 05 November 2018

This article is part of the thematic issue "Cobalt catalysis".

Guest Editor: S. Matsunaga

(C) 2018 Hiranoi and Nakano; licensee Beilstein-Institut. License and terms: see end of document.

\begin{abstract}
The alternating copolymerization of epoxides with cyclic anhydrides (CAs) is a highly diverse synthetic method for polyesters as the polymers' architectures and properties can be easily controlled depending on the combination of two monomers. Thus, a variety of catalyst designs has been reported to prepare the desired copolymers efficiently. We herein report dinuclear cobalt-salen complexes with a benzene ring as a linker and their activities in copolymerization reactions. The dinuclear cobalt complexes showed a higher catalytic activity for the copolymerization of propylene oxide with phthalic anhydride than the corresponding mononuclear cobalt-salen complex and achieved one of the highest turnover frequencies ever reported. A variety of epoxides and CAs were also found to be copolymerized successfully by the dinuclear cobalt complex with a high catalytic activity.
\end{abstract}

\section{Introduction}

Aliphatic polyesters have received significant attention owing to their good biocompatibility and biodegradability [1-4]. These attractive features allow them to be applied in medical and ecological materials as well as in commodity materials. The conventional way of synthesizing polyesters is the step-growth polymerization of diacids (or diacid derivatives) with diols. The ready availability of structurally diverse diacids and diols provides access to a wide range of polyesters. In this method, an extremely high conversion of the carboxy and hydroxy groups should be achieved for synthesizing high molecular weight polyesters. However, there are some burdensome requisites, such as a precise stoichiometric balance between the carboxy and hydroxy groups and an efficient removal of small molecule byproducts, for the high conversion. Another conventional method for polyester synthesis is the chain-growth ring-opening polymerization (ROP) of lactones and cyclic diesters [5-10]. In contrast to the step-growth polymerization, the ROP does not give any small molecule byproducts and proceeds under mild conditions. In addition, high molecular weight polyesters with narrow polydispersity can be prepared even at a low monomer 
conversion. A variety of lactones and cyclic diesters, such as $\varepsilon$-caprolactone, $\beta$-propiolactone, lactic acid (LA), and glycolide have been used for the ROP. However, the employable monomers are rather limited, which restricts the range of polymer properties.

In view of the aforementioned, the alternating copolymerization of epoxides with cyclic anhydrides (CAs) is a promising alternative for polyester synthesis $[11,12]$. A broad range of epoxides and CAs are readily available and can be copolymerized through this method. Therefore, the polymer architectures and properties can be easily controlled depending on the combination of the two monomers used. This copolymerization method was first reported in 1960 where a tertiary amine was used as a catalyst [13]. Since then, a range of polymerization catalysts including alkyl metals and inorganic salts have been reported. However, the development of the epoxide/CA copolymerization was constricted until recently because of low catalytic activity and poor control over the main chain sequence (formation of ether linkages through consecutive epoxide enchainment) and molecular weight. In 2007, Coates and co-workers reported that $\beta$-diiminate zinc complexes exhibited a high catalytic activity for the epoxide/CA copolymerization [14]. The resulting polyesters were found to possess completely alternating structures with high molecular weight and relatively narrow polydispersity. Following this report, a range of highly active and/or selective catalysts has been developed based on welldefined metal complexes such as metalloporphyrins and metal-salen complexes [15-21]. In parallel to the development of catalysts, new polyester materials also were prepared by employing unprecedented monomers or by the combination with other polymerization methods [22-26].

Cooperative dinuclear metal catalysts have been considered as a promising design for high activity and/or selectivity in organic transformations including polymerizations [27-30]. This was found to be true for the epoxide/CA copolymerization. In 2013, $\mathrm{Lu}$ and co-workers reported that the dinuclear chromium-salan complex showed a much higher catalytic activity than the corresponding mononuclear chromium-salan complex in the copolymerization of epoxides with maleic anhydride (MA) [31]. Following this report, some dinuclear metal complexes have been reported to demonstrate high and/or unique catalytic performances in the epoxide/CA copolymerization [23,32-39]. Recently, we have reported the dinuclear cobalt-salen complexes as catalysts for the copolymerization of epoxides with carbon dioxide $\left(\mathrm{CO}_{2}\right)$, affording superior catalytic activity compared to the corresponding mononuclear cobalt-salen complexes [40]. During the course of our study, the dinuclear cobalt-salen complex $(R, R, S, S)$-1 was found to exhibit a high catalytic activity for the alternating copolymerization of propylene oxide (PO) with phthalic anhydride (PA, Figure 1). The observed catalytic activity was much higher than that achieved by using the mononuclear cobalt-salen complex. Although mononuclear cobalt-salen complexes are known as one of the most active catalysts for the epoxide/CA copolymerization [15], there has been no report on the catalyst design based on dinuclear cobalt-salen complexes. This context prompted us to explore the catalyst performance of the dinuclear cobalt-salen complexes. Herein we report our further investigation on the epoxide/CA copolymerization by using dinuclear cobalt-salen complexes.

\section{Results and Discussion Synthesis of dinuclear cobalt-salen complexes}

In our previous preliminary investigation, we used the heterochiral dinuclear cobalt-salen complex $(R, R, S, S)$-1 with tertbutyl groups at the 5-positions of the salicylidene moieties and a pentafluorobenzoate group as an axial ligand [40]. Recently, the substituents at the 5-positions and the axial ligand of mononuclear cobalt-salen complexes were proven to have a great

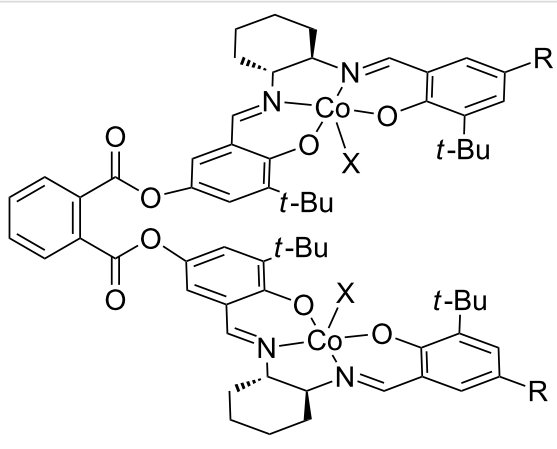

$(R, R, S, S)-1\left(\mathrm{R}=t-\mathrm{Bu}, \mathrm{X}=\mathrm{OCOC}_{6} \mathrm{~F}_{5}\right)$ $(R, R, S, S)-2\left(\mathrm{R}=\mathrm{F}, \mathrm{X}=\mathrm{NO}_{3}\right)$

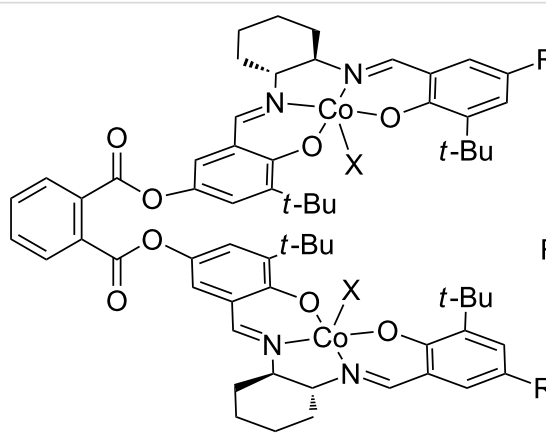

$$
R
$$

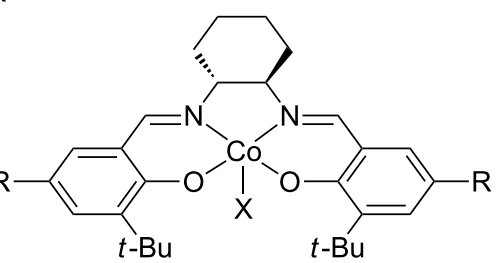

$(R, R, R, R)-1\left(\mathrm{R}=\mathrm{t}-\mathrm{Bu}, \mathrm{X}=\mathrm{OCOC}_{6} \mathrm{~F}_{5}\right)$

$(R, R, R, R)-2\left(\mathrm{R}=\mathrm{F}, \mathrm{X}=\mathrm{NO}_{3}\right)$

$(R, R)-3\left(\mathrm{R}=t-\mathrm{Bu}, \mathrm{X}=\mathrm{OCOC}_{6} \mathrm{~F}_{5}\right)$

$(R, R)-4\left(\mathrm{R}=\mathrm{F}, \mathrm{X}=\mathrm{NO}_{3}\right)$ 
impact on the catalytic activity [15]. The electron-withdrawing fluoro group at the 5-positions and a nitrate axial ligand gave the most active catalyst for the PO/MA copolymerization. Accordingly, we designed the heterochiral dinuclear cobalt-salen complex $(R, R, S, S)-\mathbf{2}$ as well as the homochiral complex $(R, R, R, R)-2$ with fluoro groups at the 5-positions and nitrate axial ligands.

The heterochiral bis(salen) ligand precursor $(R, R, S, S)-\mathbf{8}$ was synthesized according to the procedure we have reported previously (Scheme 1) [40]. First, the reaction of bis(salicylaldehyde) 5 with $(R, R)$-half-salen $\mathbf{6}$, which was prepared from $(R, R)$-1,2-cyclohexanediamine monohydrochloride and 3-tertbutyl-5-fluoro-2-hydroxybenzaldehyde, gave monosalen $(R, R)$ 7 in $39 \%$ yield. Then, the obtained mono(salen) $(R, R)-7$ was converted into the heterochiral bis(salen) ligand precursor $(R, R, S, S)-8$ in $52 \%$ yield through the condensation with $(S, S)$ half-salen 6. In addition, the homochiral bis(salen) ligand precursor $(R, R, R, R)-\mathbf{8}$ was prepared by the reaction of bis(salicylaldehyde) 5 with two equivalents of $(R, R)$-half-salen 6 in $45 \%$ yield. Both, $(R, R, S, S)-\mathbf{8}$ and $(R, R, R, R)-\mathbf{8}$ were then treated with cobalt(II) nitrate and the following oxidation under air afforded the corresponding dinuclear cobalt-salen complexes $(R, R, S, S)$-2 and $(R, R, R, R)-\mathbf{2}$, respectively.

\section{Copolymerization of propylene oxide with phthalic anhydride}

The catalysts' performances were evaluated through the copolymerization of PO with PA (Table 1). For a convenient comparison of the different catalytic systems, the catalytic activity is expressed in terms of turnover frequency [TOF, (mol of PA incorporated in the copolymer $\left.) \cdot(\mathrm{mol} \text { of Co center })^{-1} \cdot \mathrm{h}^{-1}\right]$. First, the copolymerization was conducted in the presence of the homochiral dinuclear cobalt-salen complex $(R, R, R, R)-\mathbf{1}$ and $\left[\mathrm{Ph}_{3} \mathrm{P}=\mathrm{N}=\mathrm{PPh}_{3}\right]\left[\mathrm{OCOC}_{6} \mathrm{~F}_{5}\right]\left([\mathrm{PPN}]\left[\mathrm{OCOC}_{6} \mathrm{~F}_{5}\right]\right)$ as the co-catalyst at $30{ }^{\circ} \mathrm{C}$ for $1 \mathrm{~h}$ (Table 1 , entry 1 , [PO]/[PA]/[Co] $(=2[(R, R, R, R)-1]) /[$ co-catalyst $]=4,000: 400: 1: 1)$. Since the solubility of PA in PO at $30{ }^{\circ} \mathrm{C}$ is limited, a large excess of PO over PA was used to maintain a homogeneous system. Under these conditions, a high catalytic activity with a TOF of $299 \mathrm{~h}^{-1}$ was accomplished. A decrease in the amount of co-catalyst resulted in a lower TOF (Table 1, entry 2 ) and the copolymerization did not proceed at all in the absence of co-catalyst (Table 1, entry 3). Thus, one equivalent of a co-catalyst is necessary for a high catalytic activity. A remarkably high TOF of $908 \mathrm{~h}^{-1}$ was achieved at the higher copolymerization temperature of $60^{\circ} \mathrm{C}$ (Table 1, entry 4). This is one of the highest TOF values ever reported for the metal-catalyzed $\mathrm{PO} / \mathrm{PA}$ copolymerization [41].

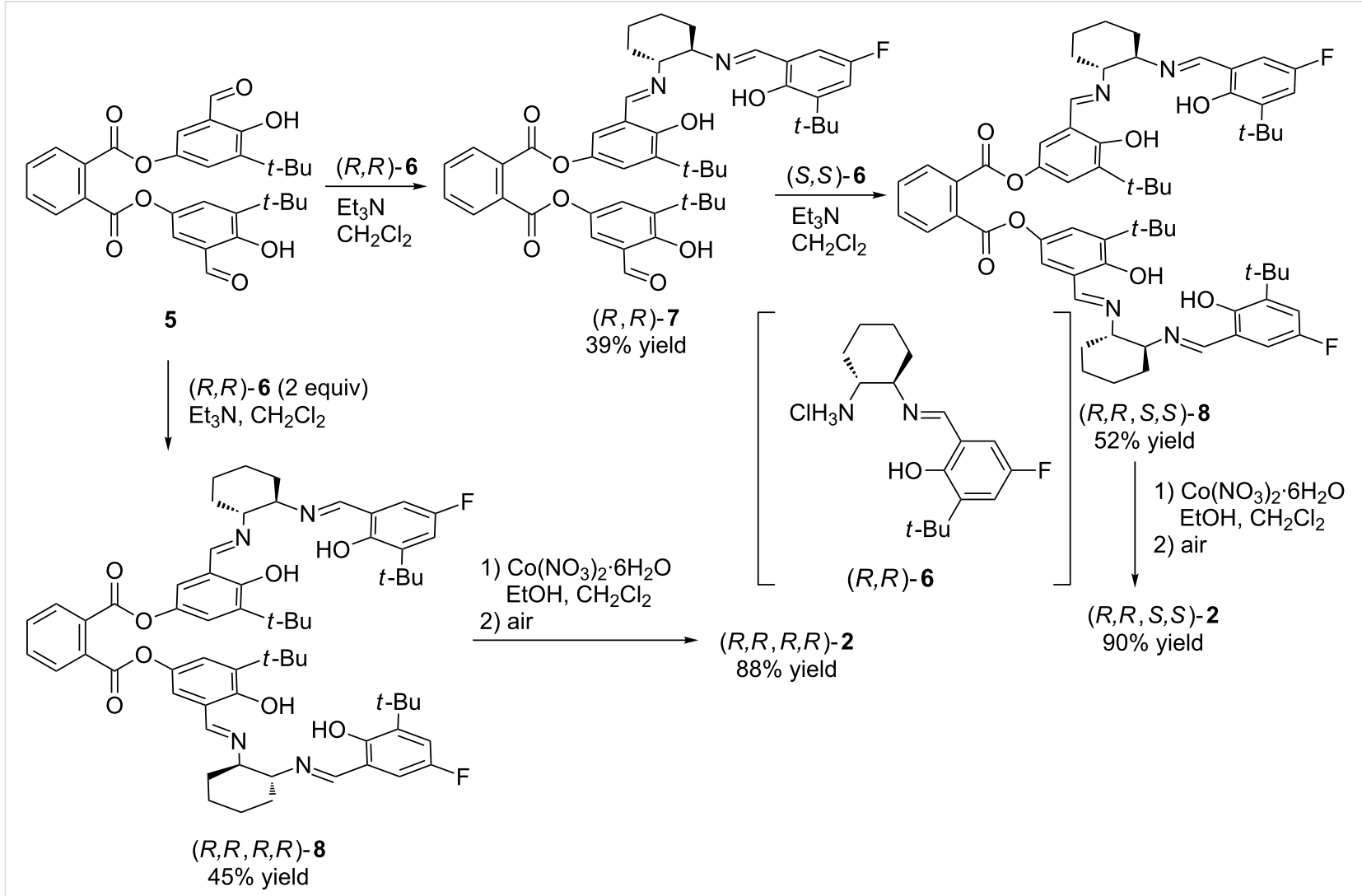

Scheme 1: Synthesis of dinuclear cobalt-salen complexes $(R, R, S, S)-2$ and $(R, R, R, R)-\mathbf{2}$. 
Table 1: Copolymerization of propylene oxide (PO) with phthalic anhydride (PA) using cobalt-salen complexes. ${ }^{a}$

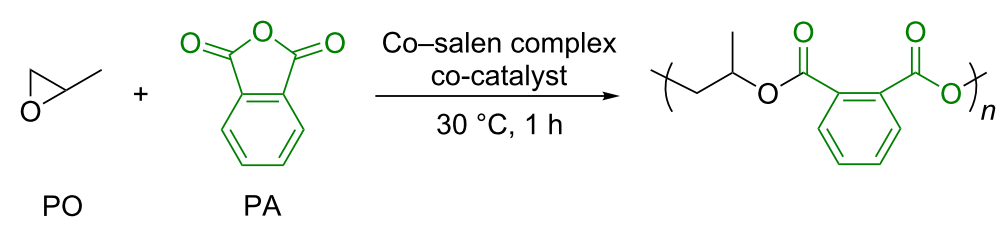

\begin{tabular}{|c|c|c|c|c|c|}
\hline entry & Co-salen complex & co-catalyst & TOF $^{\mathrm{b}}\left(\mathrm{h}^{-1}\right)$ & $M_{\mathrm{n}}^{\mathrm{c}}$ & $M_{\mathrm{w}} / M_{\mathrm{n}}{ }^{\mathrm{C}}$ \\
\hline 1 & $(R, R, R, R)-1$ & {$[\mathrm{PPN}]\left[\mathrm{OCOC}_{6} \mathrm{~F}_{5}\right]$} & 299 & 15,500 & 1.13 \\
\hline $2^{d}$ & $(R, R, R, R)-1$ & {$[\mathrm{PPN}]\left[\mathrm{OCOC}_{6} \mathrm{~F}_{5}\right]$} & 132 & 7,800 & 1.13 \\
\hline 3 & $(R, R, R, R)-1$ & & 0 & $-^{e}$ & $-^{e}$ \\
\hline $4^{f}$ & $(R, R, R, R)-1$ & {$[\mathrm{PPN}]\left[\mathrm{OCOC}_{6} \mathrm{~F}_{5}\right]$} & 908 & 12,000 & 1.14 \\
\hline $5^{9}$ & $(R, R, R, R)-1$ & {$[\mathrm{PPN}]\left[\mathrm{OCOC}_{6} \mathrm{~F}_{5}\right]$} & 149 & 7,700 & 1.18 \\
\hline 6 & $(R, R, S, S)-1$ & {$[\mathrm{PPN}]\left[\mathrm{OCOC}_{6} \mathrm{~F}_{5}\right]$} & 237 & 13,700 & 1.14 \\
\hline 7 & $(R, R)-3$ & {$[\mathrm{PPN}]\left[\mathrm{OCOC}_{6} \mathrm{~F}_{5}\right]$} & 203 & 11,400 & 1.14 \\
\hline $8^{g}$ & $(R, R)-3$ & {$[\mathrm{PPN}]\left[\mathrm{OCOC}_{6} \mathrm{~F}_{5}\right]$} & 50 & - e $^{-}$ & -e $^{\mathrm{e}}$ \\
\hline 9 & rac-3 & {$[\mathrm{PPN}]\left[\mathrm{OCOC}_{6} \mathrm{~F}_{5}\right]$} & 207 & 13,600 & 1.16 \\
\hline 10 & $(R, R, R, R)-2$ & {$[\mathrm{PPN}]\left[\mathrm{NO}_{3}\right]$} & 33 & $-^{e}$ & $-^{e}$ \\
\hline 11 & $(R, R, R, R)-2$ & {$[\mathrm{PPN}]\left[\mathrm{OCOC}_{6} \mathrm{~F}_{5}\right]$} & 31 & $-\mathrm{e}$ & $-\mathrm{e}$ \\
\hline 12 & $(R, R, S, S)-2$ & {$[\mathrm{PPN}]\left[\mathrm{NO}_{3}\right]$} & 12 & $-^{e}$ & -e $^{e}$ \\
\hline 13 & $r a c-4$ & {$[\mathrm{PPN}]\left[\mathrm{NO}_{3}\right]$} & 107 & 5,400 & 1.25 \\
\hline
\end{tabular}

acopolymerization conditions: PO $(20 \mathrm{mmol}), \mathrm{PA}(2.0 \mathrm{mmol})$, cobalt complex, and [PPN][OCOC $\left.6 \mathrm{~F}_{5}\right]$ as co-catalyst at $30{ }^{\circ} \mathrm{C}$ for $1 \mathrm{~h}$. $[\mathrm{PO}] /[\mathrm{PA}] /[\mathrm{Co}] /[\mathrm{co}-$ catalyst $]=4,000: 400: 1: 1{ }^{\mathrm{b}}$ Turnover frequency $(\mathrm{TOF})=(\mathrm{mol}$ of PA incorporated in the copolymer $) \cdot(\mathrm{mol} \text { of Co center })^{-1} \cdot \mathrm{h}^{-1} \mathrm{calcu}^{-}$ lated based on the ${ }^{1} \mathrm{H}$ NMR spectrum of the polymerization mixture using phenanthrene as an internal standard. ${ }^{\mathrm{C}}$ Estimated by size-exclusion-chro-

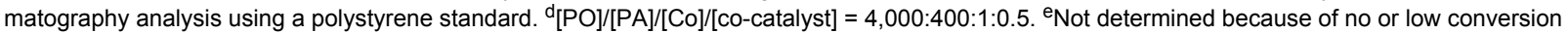
of PA. ${ }^{f} 60^{\circ} \mathrm{C}$ for $15 \mathrm{~min} .9[\mathrm{PO}] /[\mathrm{PA}] /[\mathrm{Co}] /[$ co-catalyst $]=4,000: 400: 0.25: 0.25$.

As there were no detectable signal for ether linkages in the ${ }^{1} \mathrm{H}$ NMR spectra of the obtained copolymers, the resulting copolymers possess a completely alternating structure. The regioselectivity in the ring-opening of PO was estimated by analyzing the stereochemistry of the copolymer prepared from enantiomerically pure $(S)$-PO. Because a ring opening at the methine carbon results in both a regioerror and the inversion of stereochemistry at the stereocenter, the enantiomeric excess (ee) of the repeating unit in the copolymer should reflect the regioregularity [15]. The ee of propylene glycol, which was obtained after hydrolysis of the copolymer obtained with $(S)$-PO and PA, was found to be $88 \%$, indicating a high level of regioregularity. Molecular weight distributions are relatively narrow, while a bimodal distribution was observed in the SEC traces. The peak molecular weight of the higher molecular weight portion was twice as large as that of the lower molecular weight portion. Accordingly, trace amounts of diacid in PA and/or water contaminants would work as bifunctional chaintransfer agents and gave twice the molecular weight of the copolymer initiated by monofunctional pentafluorobenzoate from $(R, R, S, S)-\mathbf{1}$ and $[\mathrm{PPN}]\left[\mathrm{OCOC}_{6} \mathrm{~F}_{5}\right]$ [19]. The formation of the alternating copolymers initiated by monofunctional pentafluorobenzoate and the bifunctional chain-transfer agents was confirmed by matrix-assisted laser desorption/ionization timeof-flight mass spectrometry (MALDI-TOF MS, Figure 2). Several series of signals with a regular interval of 206.1 (repeating unit) were observed in the lower mass range. The $\mathrm{m} / \mathrm{z}$ value of each signal of the major distribution corresponds with $\left[166.0\left(\mathrm{C}_{6} \mathrm{~F}_{5} \mathrm{COO}\right.\right.$, initiating group) $+206.1 n$ (repeating unit $)+59.1\left(\mathrm{CH}_{2} \mathrm{CHMeOH}\right.$, terminal group $)+23.0\left(\mathrm{Na}^{+}\right.$ion $\left.)\right]$. Thus, the expected $\alpha-\mathrm{C}_{6} \mathrm{~F}_{5} \mathrm{COO}, \omega$-OH-terminated copolymer was obtained as a main product. As a minor distribution, the $\alpha-\mathrm{C}_{6} \mathrm{~F}_{5} \mathrm{COO}, \omega-\mathrm{COOH}$-terminated copolymer was observed, while the cyclic polyester via intramolecular transesterification was not detected (Supporting Information File 1, Figure S14). In a higher mass range, a series of signals for the copolymer with hydroxy groups at both chain ends (the $\alpha-\mathrm{OH}, \omega-\mathrm{OH}$-terminated copolymer) was observed as the major distribution along with the $\alpha-\mathrm{OH}, \omega-\mathrm{COOH}$-terminated copolymer as the minor distribution.

Next, we investigated the effect of linking two cobalt-salen complexes on the catalytic activity. The heterochiral complex $(R, R, S, S)-\mathbf{1}$ demonstrated a much lower TOF of $237 \mathrm{~h}^{-1}$ than the homochiral one $(R, R, R, R)-\mathbf{1}$ (Table 1 , entry 6). Thereby, a combination of the same absolute configuration of two salen 


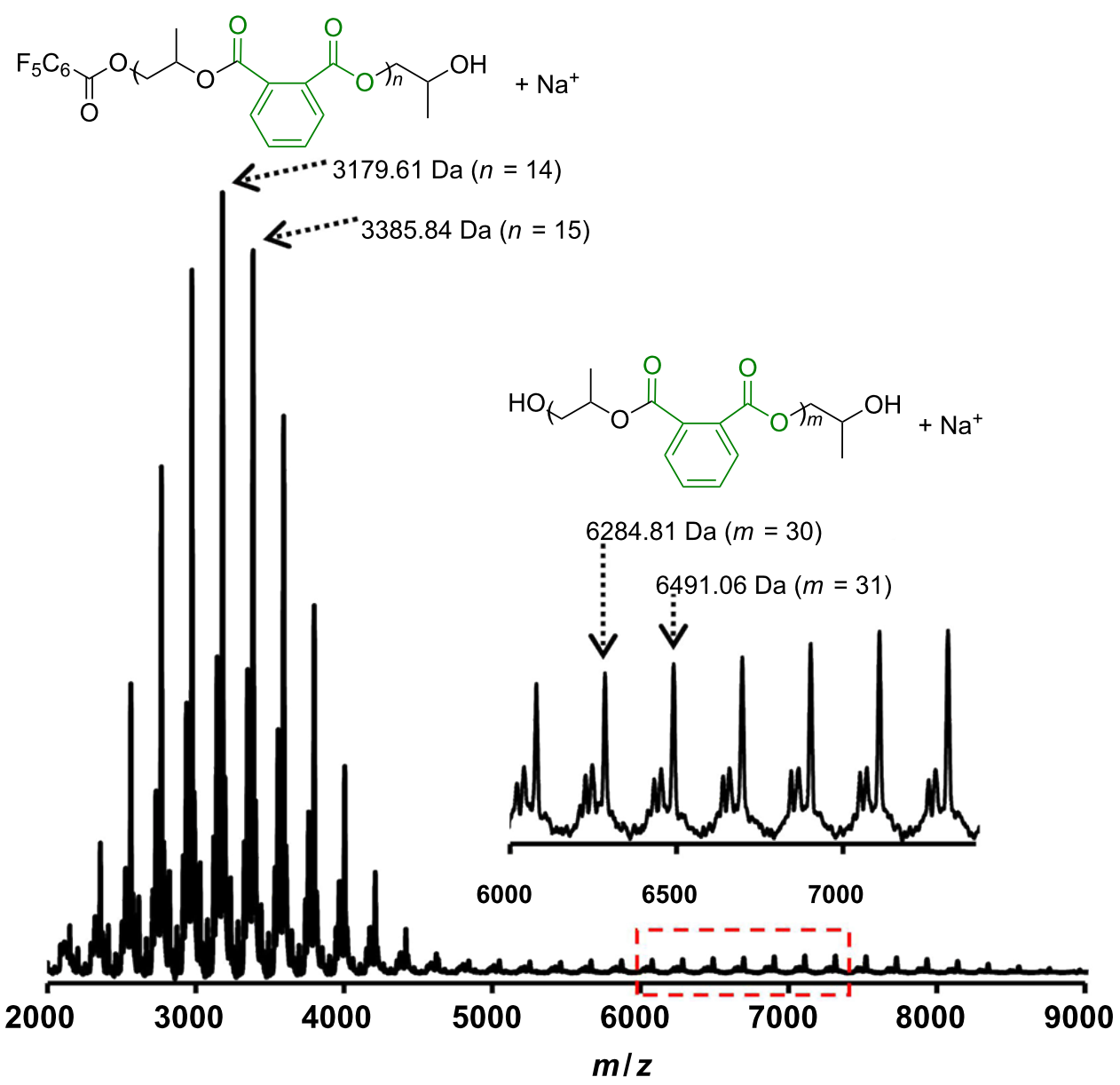

Figure 2: MALDI-TOF mass spectrum of the PO/PA copolymer. The low molecular weight copolymer for MS analysis was prepared by using $(R, R, R, R)-1$ at $30^{\circ} \mathrm{C}$ for $15 \mathrm{~min}$.

moieties was found to be favorable for a high catalytic activity. Such dependence of the catalytic activity on the absolute configuration contrasts with our previous observation in the epoxide $/ \mathrm{CO}_{2}$ copolymerization where the heterochiral $(R, R, S, S)$-1 showed a much higher catalytic activity than the corresponding homochiral complex $(R, R, R, R)-1$ [40]. Both mononuclear complexes $(R, R)-\mathbf{3}$ and rac-3 demonstrated similar and relatively high TOFs of 203 and $207 \mathrm{~h}^{-1}$, respectively (Table 1 entries 7 and 9). However, these TOFs are lower than those obtained with the dinuclear complexes $(R, R, R, R)-\mathbf{1}$ and $(R, R, S, S)$-1. When the catalyst loading was reduced to one fourth, the TOFs of the dinuclear complex $(R, R, R, R)-\mathbf{1}$ and the mononuclear complex $(R, R)-3$ fell to about one half and one quarter, respectively (Table 1, entries 5 and 8 ). Thus, the dinuclear complex $(R, R, R, R)-\mathbf{1}$ was found to be less affected by the catalyst loading. It is unclear whether the copolymerization proceeds via bimetallic propagation mechanism in the present catalyst systems. Nevertheless, these results indicated that the linking of two (or more) cobalt-salen complexes is a promising design for highly active catalysts.
The effect of substituents on the salen moieties and the axial ligands on the cobalt centers was also investigated. As mentioned above, fluoro substituents at 5-positions of the salicylidene moieties and a nitrate axial ligand on the cobalt center were reported to be an optimal combination for the PO/MA copolymerization with mononuclear cobalt-salen complexes [15]. Therefore, we expected that the dinuclear cobalt-salen complexes $(R, R, R, R)-\mathbf{2}$ and $(R, R, S, S)-\mathbf{2}$ would give higher catalytic activities than complexes $\mathbf{1}$. The homochiral and heterochiral complexes $\mathbf{2}$ efficiently copolymerized PO with PA and showed TOFs of 33 and $12 \mathrm{~h}^{-1}$, respectively, again demonstrating dependence of the catalytic activity on the absolute configuration (Table 1, entries 10 and 12). However, the TOFs unexpectedly are much lower than those obtained by using $(R, R, R, R)-1$ and $(R, R, S, S)$-1. This trend was also observed for mononuclear complexes: the mononuclear complex rac-4 with fluoro substituents at the 5-positions and a nitrate axial ligand gave a much lower TOF than rac-3 (Table 1, entry 13). In addition, the TOF obtained with $(R, R, R, R)-2$ and $[\mathrm{PPN}]\left[\mathrm{OCOC}_{6} \mathrm{~F}_{5}\right]$ was almost identical to that with $[\mathrm{PPN}]\left[\mathrm{NO}_{3}\right]$ (Table 1, entries 
11 and 10). Therefore, tert-butyl substituents and a pentafluorobenzoate axial ligand were found to be more suitable for the $\mathrm{PO} / \mathrm{PA}$ copolymerization. It should also be noted that the linking of two complexes has a negative impact on catalytic activity in the case of the cobalt-salen complex with a fluoro substituent and a nitrate axial ligand (Table 1, entries 10 and 13).

\section{Monomer scope}

In order to evaluate the copolymerization scope, the dinuclear cobalt-salen complex $(R, R, R, R)-\mathbf{1}$ and co-catalyst $[\mathrm{PPN}]\left[\mathrm{OCOC}_{6} \mathrm{~F}_{5}\right]$ were employed for the copolymerization of other epoxides with PA (Table 2). 1-Hexene oxide (HO), a terminal epoxide with an expanded alkyl chain, can be copolymerized at $30{ }^{\circ} \mathrm{C}$ to afford a completely alternating copolymer, while the TOF $\left(61 \mathrm{~h}^{-1}\right)$ was much lower than that obtained for the PO/PA copolymerization (Table 2, entry 1 ). A higher polymerization temperature improved the TOF up to $399 \mathrm{~h}^{-1}$ and almost complete conversion of PA was achieved within $1 \mathrm{~h}$ (Table 2, entry 2). The copolymerization with cyclohexene oxide (CHO), a common alicyclic epoxide in epoxide/CA copolymerization, also gave the corresponding alternating copolymer (Table 2, entries 3 and 4). The TOF of $244 \mathrm{~h}^{-1}$ was achieved at $60{ }^{\circ} \mathrm{C}$, which was the highest one ever reported for a CHO/PA copolymerization. The copolymerization of PO with other CAs was also tested to evaluate the scope. Cyclohexane dicarboxylic anhydride (CHDA) was successfully converted into the corresponding polyester with a TOF of $53 \mathrm{~h}^{-1}$ (Table 2, entry 5). The copolymerization with maleic anhydride (MA), a common $\mathrm{CA}$ in the epoxide/CA copolymerization, took place (Table 2, entries 6 and 7). However, the TOF was low even at a higher temperature. The mononuclear cobalt-salen complex with fluoro substituents at 5-positions of the salicylidene moieties and a nitrate axial ligand on the cobalt center was reported to be most active for PO/MA copolymerization [15]. Thus, we also applied complex $(R, R, R, R)-2$ with $[\mathrm{PPN}]\left[\mathrm{NO}_{3}\right]$ as co-catalyst in the copolymerization. As a result, the complex was found to show a slightly higher activity compared with $(R, R, R, R)-1$ although the TOF was much lower than that obtained with the mononuclear complex (Table 2, entry 8). Finally, we attempted the terpolymerization of PO, HO, and PA (Scheme 2). Although equimolar amounts of PO and HO were used, the obtained copolymer contained a larger amount of the PO-derived repeating unit, reflecting a higher reactivity of PO.

\section{Conclusion}

We reported the alternating copolymerization of epoxides with cyclic anhydrides using dinuclear cobalt-salen complexes with a benzene linker. The substituents on the salen moieties, an

Table 2: Copolymerization of various epoxides and cyclic anhydrides. ${ }^{a}$<smiles>[R]C1OC1[R]</smiles>
epoxide
$(R, R, R, R)-1$ [PPN][OCOC $\left.6 \mathrm{~F}_{5}\right]$ temperature, time

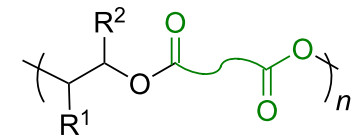
CA
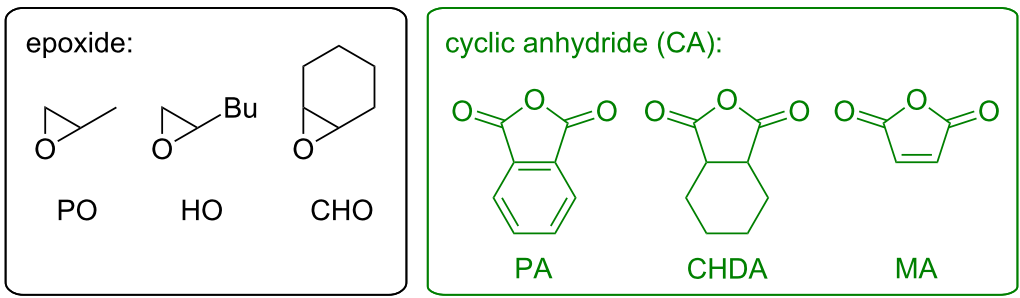

\begin{tabular}{|c|c|c|c|c|c|c|c|}
\hline entry & monomer & $T\left({ }^{\circ} \mathrm{C}\right)$ & time $(h)$ & [epoxide]/[CA]/[Co]/[co-catalyst] & $\mathrm{TOF}^{\mathrm{b}}\left(\mathrm{h}^{-1}\right)$ & $M_{\mathrm{n}}^{\mathrm{c}}$ & $M_{\mathrm{w}} / M_{\mathrm{n}}{ }^{\mathrm{C}}$ \\
\hline 1 & $\mathrm{HO} / \mathrm{PA}$ & 30 & 2 & $2,400: 400: 1: 1$ & 61 & 8,400 & 1.20 \\
\hline 2 & $\mathrm{HO} / \mathrm{PA}$ & 60 & 1 & $2,400: 400: 1: 1$ & 399 & 22,000 & 1.18 \\
\hline 3 & $\mathrm{CHO} / \mathrm{PA}$ & 30 & 2 & $2,800: 400: 1: 1$ & 20 & 500 & 1.97 \\
\hline 4 & CHO/PA & 60 & 1 & $2,800: 400: 1: 1$ & 244 & 7,000 & 1.16 \\
\hline 5 & $\mathrm{PO} / \mathrm{CHDA}$ & 30 & 2 & $4,000: 400: 1: 1$ & 53 & 1,400 & 2.06 \\
\hline 6 & PO/MA & 30 & 2 & $2,000: 200: 1: 1$ & 10 & $-^{d}$ & $-d$ \\
\hline 7 & $\mathrm{PO} / \mathrm{MA}$ & 60 & 1.5 & $2,000: 200: 1: 1$ & 39 & $-d$ & $-d$ \\
\hline $8^{e}$ & $\mathrm{PO} / \mathrm{MA}$ & 30 & 2 & $2,000: 200: 1: 1$ & 22 & $-d$ & $-d$ \\
\hline
\end{tabular}

aCopolymerization conditions: epoxide, $\mathrm{CA}(2.0 \mathrm{mmol}$ for entries $1-5 ; 1.0 \mathrm{mmol}$ for entries $6-8)$, cobalt complex, [PPN][OCOC $\left.6 \mathrm{~F}_{5}\right]$ as a co-catalyst.

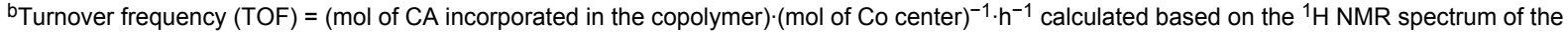
polymerization mixture using phenanthrene as an internal standard. ' Estimated by size-exclusion-chromatography analysis using a polystyrene standard. ${ }^{\mathrm{d}}$ Not determined because of low conversion of MA. ${ }^{\mathrm{e}}(R, R, R, R)-2$ and $[\mathrm{PPN}]\left[\mathrm{NO}_{3}\right]$. 


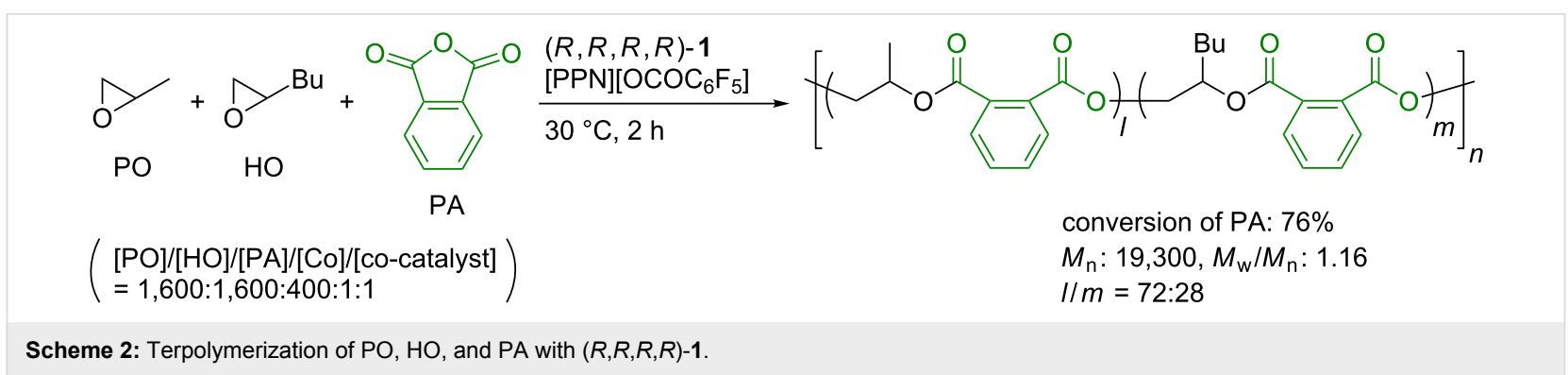

axial ligand on the cobalt center, and a combination of the absolute configuration of the two cobalt-salen moieties were found to have a great impact on the catalytic activity. Through these investigations, the homochiral dinuclear cobalt-salen complex having tert-butyl substituents and a pentafluorobenzoate axial ligand was developed as a highly active catalyst. Furthermore, the dinuclear cobalt-salen complex demonstrated a higher catalytic activity than the corresponding mononuclear cobalt-salen complex. These results indicate that the design based on di- or multinuclear metal complexes is a promising strategy for the development of highly active catalysts. Our future studies will focus on the optimization of linker structures as well as ligand structures for the epoxide/CA copolymerization to achieve higher activity and/or selectivity.

\section{Experimental}

General procedures: All manipulations involving air and/or moisture-sensitive compounds were carried out using standard Schlenk techniques under argon. Analytical thin-layer chromatography was performed on glass plates coated with $0.25 \mathrm{~mm}$ 230-400 mesh silica gel containing a fluorescence indicator. Column chromatography was performed on silica gel (spherical neutral, particle size: $63-210 \mu \mathrm{m}$ ). Most of the reagents were purchased from commercial suppliers, such as Sigma-Aldrich Co. LLC, Tokyo Chemical Industry Co., Ltd., and Kanto Chemical Co., Inc., and were used without further purification unless otherwise specified. Commercially available anhydrous solvents were used for air and/or moisture-sensitive reactions. Epoxides for the polymerizations were dried over $\mathrm{CaH}_{2}$ and distilled under argon and cyclic anhydrides were purified by sublimation. $(R, R, S, S)$ - and $(R, R, R, R)-\mathbf{1}[40],(R, R)$ - and rac-3 [42], rac-4 [15], 5 [40], [PPN] $\left[\mathrm{OCOC}_{6} \mathrm{~F}_{5}\right]$ [42], and $[\mathrm{PPN}]\left[\mathrm{NO}_{3}\right][15]$ were prepared according to the literature.

NMR spectra were recorded in $\mathrm{CDCl}_{3}$ on a JEOL-ECX400 spectrometer $\left({ }^{1} \mathrm{H} \mathrm{NMR}\right.$ at $400 \mathrm{MHz} ;{ }^{13} \mathrm{C} \mathrm{NMR}$ at $\left.101 \mathrm{MHz}\right)$ or a JEOL-ECA500 spectrometer ( ${ }^{19} \mathrm{~F}$ NMR at $\left.471 \mathrm{MHz}\right)$. Chemical shifts are reported in $\mathrm{ppm}$ relative to the internal standard signal (0 ppm for $\mathrm{Me}_{4} \mathrm{Si}$ in $\mathrm{CDCl}_{3}$ ) for ${ }^{1} \mathrm{H} \mathrm{NMR}$ and the solvent signal (77.16 ppm for $\mathrm{CDCl}_{3}$ ) for ${ }^{13} \mathrm{C} \mathrm{NMR}$. Data are presented as follows: chemical shift, multiplicity ( $\mathrm{s}=$ singlet, $\mathrm{d}=$ doublet, $\mathrm{dd}=$ doublet of doublets, $\mathrm{m}=$ multiplet and/or multiple resonances), coupling constant in hertz $(\mathrm{Hz})$, and signal area integration in natural numbers. High resolution mass spectra are taken with a Bruker Daltonics micrOTOF-QII mass spectrometer by atmospheric pressure chemical ionization-time-of-flight (APCI-TOF) method. Sizeexclusion-chromatography (SEC) analyses for evaluating molecular weights were carried with two columns (Shodex $\mathrm{KF}-804 \mathrm{~L}$ ) using chloroform as an eluent at $40{ }^{\circ} \mathrm{C}$ at $1 \mathrm{~mL} / \mathrm{min}$. The molecular weight was calibrated against standard polystyrene samples. The recycling preparative HPLC was performed with YMC-GPC T-2000 and T-4000 columns (chloroform as an eluent). HPLC analysis for determining the ee was carried out using a DAICEL CHIRALCEL ${ }^{\circledR}$ IA-3 column $(4.6 \mathrm{~mm} \times 250 \mathrm{~mm})$.

Synthesis of mono(salen) $(\boldsymbol{R}, \boldsymbol{R})-7$ : A Schlenk tube was charged with $(R, R)$-1,2-cyclohexanediamine monohydrochloride ( $0.14 \mathrm{~g}, 0.93 \mathrm{mmol})$, 3-tert-butyl-5-fluoro-2-hydroxybenzaldehyde $(0.18 \mathrm{~g}, 0.93 \mathrm{mmol})$, molecular sieves $4 \AA$, and dry $\mathrm{MeOH}(1.5 \mathrm{~mL})$ under argon. After stirring at room temperature for $50 \mathrm{~min}$, the resulting solution was slowly transferred to another Schlenk tube containing bis(salicylaldehyde) 5 (0.72 g, $1.4 \mathrm{mmol}), \mathrm{Et}_{3} \mathrm{~N}(0.47 \mathrm{~mL}, 3.4 \mathrm{mmol})$ and dichloromethane $(7 \mathrm{~mL})$. The reaction mixture was stirred at room temperature for $18 \mathrm{~h}$ and the resulting suspension was filtered off with dichloromethane. The filtrate was concentrated under reduced pressure and the crude residue was purified by silica-gel column chromatography (AcOEt/hexane/Et ${ }_{3} \mathrm{~N}$ 1:5:0.12 as an eluent, $R_{\mathrm{f}} 0.30$ ] to provide $(R, R)-7(0.36 \mathrm{~g}, 39 \%$ yield $)$ as yellow solid: ${ }^{1} \mathrm{H} \mathrm{NMR}\left(400 \mathrm{MHz}, \mathrm{CDCl}_{3}\right) \delta 11.73(\mathrm{~s}, 1 \mathrm{H}), 9.75(\mathrm{~s}, 1 \mathrm{H}), 8.24$ (s, 1H), $8.19(\mathrm{~s}, 1 \mathrm{H}), 7.99-7.92(\mathrm{~m}, 2 \mathrm{H}), 7.71-7.67(\mathrm{~m}, 2 \mathrm{H})$, 7.29 (s, 2H), 7.04 (d, $J=2.7 \mathrm{~Hz}, 1 \mathrm{H}), 6.98(\mathrm{dd}, J=11.0$, $3.2 \mathrm{~Hz}, 1 \mathrm{H}), 6.90(\mathrm{~d}, J=2.7 \mathrm{~Hz}, 1 \mathrm{H}), 6.70(\mathrm{dd}, J=7.8,3.2 \mathrm{~Hz}$, $1 \mathrm{H}), 3.40-3.28$ (m, 2H), 2.00-1.88 (m, 4H), 1.76-1.68 (m, 2H), $1.52-1.45(\mathrm{~m}, 2 \mathrm{H}), 1.36(\mathrm{~s}, 9 \mathrm{H}), 1.32(\mathrm{~s}, 18 \mathrm{H}) ;{ }^{13} \mathrm{C} \mathrm{NMR}$ $\left(101 \mathrm{MHz}, \mathrm{CDCl}_{3}\right) \delta 196.5,166.5,166.3,164.7,159.3,158.6$, $156.5,155.0\left(\mathrm{~d}, J_{\mathrm{C}-\mathrm{F}}=234.8 \mathrm{~Hz}\right), 142.6,141.7,140.4,139.4$ $\left(\mathrm{d}, J_{\mathrm{C}-\mathrm{F}}=4.8 \mathrm{~Hz}\right), 139.1,132.0,131.9,131.8,131.7,129.8$, 129.6, 128.1, 128.0, 123.4, 122.9, 121.3, 120.2, 118.3, 118.1 (d, $\left.J_{\mathrm{C}-\mathrm{F}}=7.7 \mathrm{~Hz}\right), 117.1\left(\mathrm{~d}, J_{\mathrm{C}-\mathrm{F}}=24.9 \mathrm{~Hz}\right), 114.2(\mathrm{~d}$, 
$\left.J_{\mathrm{C}-\mathrm{F}}=22.0 \mathrm{~Hz}\right), 72.7,72.1,35.1,35.0,33.2,33.0,29.23,29.15$, 29.0, 24.34, 24.29; ${ }^{19} \mathrm{~F}$ NMR (471 MHz, $\left.\mathrm{CDCl}_{3}\right) \delta-126.3$; HRMS-APCI ${ }^{+}(m / z):[\mathrm{M}+\mathrm{H}]^{+}$calcd for $\mathrm{C}_{47} \mathrm{H}_{54} \mathrm{FN}_{2} \mathrm{O}_{8}$, 793.3859; found, 793.3859.

Synthesis of bis(salen) $(\boldsymbol{R}, \boldsymbol{R}, S, S)-8$ : The crude product was obtained from $(S, S)$-1,2-cyclohexanediamine monohydrochloride (28 mg, $0.19 \mathrm{mmol}$ ), 3-tert-butyl-5-fluoro-2-hydroxybenzaldehyde (37 mg, $0.19 \mathrm{mmol}),(R, R)-7(0.13 \mathrm{~g}, 0.17 \mathrm{mmol})$, and $\mathrm{Et}_{3} \mathrm{~N}(0.11 \mathrm{~mL}, 0.79 \mathrm{mmol})$ according to the procedure described for the synthesis of $(R, R)-7$. Purification by silica gel column chromatography (AcOEt/hexane/Et ${ }_{3} \mathrm{~N}$ 1:5:0.12 as an eluent, $\left.R_{\mathrm{f}} 0.38\right)$ gave $(R, R, S, S)-8(95 \mathrm{mg}, 52 \%$ yield) as yellow solid: ${ }^{1} \mathrm{H}$ NMR $\left(400 \mathrm{MHz}, \mathrm{CDCl}_{3}\right) \delta 8.24(\mathrm{~s}, 2 \mathrm{H}), 8.17(\mathrm{~s}, 2 \mathrm{H})$, 7.93-7.89 (m, 2H), 7.67-7.62 (m, 2H), $7.01(\mathrm{~d}, J=2.7 \mathrm{~Hz}, 2 \mathrm{H})$, $6.98(\mathrm{dd}, J=11.0,3.2 \mathrm{~Hz}, 1 \mathrm{H}), 6.88(\mathrm{~d}, J=2.7 \mathrm{~Hz}, 2 \mathrm{H}), 6.70$ (dd, $J=7.8,2.7 \mathrm{~Hz}, 2 \mathrm{H}), 3.38-3.28(\mathrm{~m}, 4 \mathrm{H}), 2.00-1.88(\mathrm{~m}$, $8 \mathrm{H}), 1.79-1.66(\mathrm{~m}, 4 \mathrm{H}), 1.52-1.45(\mathrm{~m}, 4 \mathrm{H}), 1.37$ (s, 9H), 1.36 $(\mathrm{s}, 9 \mathrm{H}), 1.27(\mathrm{~s}, 18 \mathrm{H}) ;{ }^{13} \mathrm{C} \mathrm{NMR}\left(101 \mathrm{MHz}, \mathrm{CDCl}_{3}\right) \delta 166.4$, $164.8,164.7\left(\mathrm{~d}, J_{\mathrm{C}-\mathrm{F}}=1.9 \mathrm{~Hz}\right), 158.5,156.5,155.0(\mathrm{~d}$, $\left.J_{\mathrm{C}-\mathrm{F}}=234.8 \mathrm{~Hz}\right), 141.8,139.4\left(\mathrm{~d}, J_{\mathrm{C}-\mathrm{F}}=5.8 \mathrm{~Hz}\right), 139.0,131.9$, $131.8,129.6,123.0,121.4,118.3,118.1\left(\mathrm{~d}, J_{\mathrm{C}-\mathrm{F}}=7.7 \mathrm{~Hz}\right)$, $117.1\left(\mathrm{~d}, J_{\mathrm{C}-\mathrm{F}}=24.0 \mathrm{~Hz}\right), 114.2\left(\mathrm{~d}, J_{\mathrm{C}-\mathrm{F}}=22.0 \mathrm{~Hz}\right), 72.8,72.0$, $35.1,35.0,33.2,33.0,29.3,29.1,24.35,24.29 ;{ }^{19} \mathrm{~F}$ NMR $\left(471 \mathrm{MHz}, \mathrm{CDCl}_{3}\right) \delta-126.3$; HRMS-APCI ${ }^{+}(\mathrm{m} / \mathrm{z}):[\mathrm{M}+\mathrm{H}]^{+}$ calcd for $\mathrm{C}_{64} \mathrm{H}_{77} \mathrm{~F}_{2} \mathrm{~N}_{4} \mathrm{O}_{8}{ }^{+}$, 1067.5704; found, 1067.5697.

Synthesis of bis(salen) $(\boldsymbol{R}, \boldsymbol{R}, \boldsymbol{R}, \boldsymbol{R})-8$ : The crude product was obtained from $(R, R)$-1,2-cyclohexanediamine monohydrochloride $(0.10 \mathrm{~g}, 0.66 \mathrm{mmol}), 3$-tert-butyl-5-fluoro-2-hydroxybenzaldehyde (0.13 g, $0.66 \mathrm{mmol})$, bis(salicylaldehyde) 5 (0.15 g, $0.30 \mathrm{mmol})$, and $\mathrm{Et}_{3} \mathrm{~N}(0.14 \mathrm{~mL}, 1.0 \mathrm{mmol})$ according to the procedure described for the synthesis of $(R, R)-7$. Purification by silica gel column chromatography (AcOEt/hexane/Et ${ }_{3} \mathrm{~N}$ 1:5:0.12 as an eluent, $\left.R_{\mathrm{f}} 0.38\right)$ gave $(R, R, R, R)-8(145 \mathrm{mg}$, $45 \%$ yield) as yellow solid: ${ }^{1} \mathrm{H}$ NMR $\left(400 \mathrm{MHz}, \mathrm{CDCl}_{3}\right) \delta 8.24$ (s, 2H), 8.17 (s, 2H), 7.93-7.89 (m, 2H), 7.68-7.63 (m, 2H), $7.01(\mathrm{~d}, J=3,2 \mathrm{~Hz}, 2 \mathrm{H}), 6.98(\mathrm{dd}, J=11.0,2.7 \mathrm{~Hz}, 1 \mathrm{H}), 6.88$ $(\mathrm{d}, J=2.7 \mathrm{~Hz}, 2 \mathrm{H}), 6.70(\mathrm{dd}, J=7.8,3.2 \mathrm{~Hz}, 2 \mathrm{H}), 3.38-3.27$ (m, 4H), 2.00-1.88 (m, 8H), 1.79-1.66 (m, 4H), 1.52-1.44 (m, $4 \mathrm{H}), 1.36(\mathrm{~s}, 18 \mathrm{H}), 1.27(\mathrm{~s}, 18 \mathrm{H}) ;{ }^{13} \mathrm{C} \mathrm{NMR}\left(101 \mathrm{MHz}, \mathrm{CDCl}_{3}\right)$ $\delta 166.5,164.8,164.7\left(\mathrm{~d}, J_{\mathrm{C}-\mathrm{F}}=2.9 \mathrm{~Hz}\right), 158.5,156.5,155.0(\mathrm{~d}$, $\left.J_{\mathrm{C}-\mathrm{F}}=234.8 \mathrm{~Hz}\right), 141.8,139.4\left(\mathrm{~d}, J_{\mathrm{C}-\mathrm{F}}=5.8 \mathrm{~Hz}\right), 139.0,131.9$, $131.8,129.6,123.0,121.4,118.3,118.1\left(\mathrm{~d}, J_{\mathrm{C}-\mathrm{F}}=7.7 \mathrm{~Hz}\right)$, $117.1\left(\mathrm{~d}, J_{\mathrm{C}-\mathrm{F}}=24.0 \mathrm{~Hz}\right), 114.2\left(\mathrm{~d}, J_{\mathrm{C}-\mathrm{F}}=23.0 \mathrm{~Hz}\right), 72.8,72.0$, 35.1, 35.0, 33.2, 33.0, 29.2, 29.1, 24.34, 24.28; HRMS-APCI ${ }^{+}$ $(m / z):[\mathrm{M}+\mathrm{H}]^{+}$calcd for $\mathrm{C}_{64} \mathrm{H}_{77} \mathrm{~F}_{2} \mathrm{~N}_{4} \mathrm{O}_{8}{ }^{+}, 1067.5704$; found, 1067.5702 .

Synthesis of dinuclear Co-salen complex $(R, R, S, S)-2$ : A Schlenk tube was charged with $\mathrm{Co}\left(\mathrm{NO}_{3}\right)_{2} \cdot 6 \mathrm{H}_{2} \mathrm{O}(52 \mathrm{mg}$,
$0.18 \mathrm{mmol})$. After stirring at $60{ }^{\circ} \mathrm{C}$ under reduced pressure for $1.5 \mathrm{~h}$, EtOH $(2.0 \mathrm{~mL})$ was added. Another Schlenk tube was charged with $(R, R, S, S)-8(88 \mathrm{mg}, 80 \mu \mathrm{mol})$ and degassed $\mathrm{CH}_{2} \mathrm{Cl}_{2}(3.0 \mathrm{~mL})$ added under argon. After the solution of $\mathrm{Co}\left(\mathrm{NO}_{3}\right)_{2}$ was slowly added to the ligand solution, the resulting mixture was stirred at room temperature for $1 \mathrm{~h}$, and then opened to air. The reaction mixture was stirred at room temperature for $13 \mathrm{~h}$, filtered, and concentrated under reduced pressure. The resulting residue was rinsed with pentane until the filtrate was clear, and then dried at $60{ }^{\circ} \mathrm{C}$ under reduced pressure to provide ( $R, R, S, S)-2$ (94 mg, $90 \%$ yield for two steps) as dark green powder: $\mathrm{HRMS}-\mathrm{APCI}^{+}(\mathrm{m} / \mathrm{z}):\left[\mathrm{M}+\mathrm{H}-2\left(\mathrm{NO}_{3}\right)\right]^{+}$ calcd for $\mathrm{C}_{64} \mathrm{H}_{73} \mathrm{Co}_{2} \mathrm{~F}_{2} \mathrm{~N}_{4} \mathrm{O}_{8}{ }^{+}, 1181.4055$; found, 1181.4054; anal. calcd for $\mathrm{C}_{64} \mathrm{H}_{72} \mathrm{Co}_{2} \mathrm{~F}_{2} \mathrm{~N}_{6} \mathrm{O}_{14}(\%)$ : C, 58.90; $\mathrm{H}, 5.56 ; \mathrm{N}$, 6.44; found: C, 55.84; H, 5.82; N, 5.33.

Synthesis of dinuclear Co-salen complex $(\boldsymbol{R}, \boldsymbol{R}, \boldsymbol{R}, \boldsymbol{R})-2$ : Complex $(R, R, R, R)-2$ was obtained from $\mathrm{Co}\left(\mathrm{NO}_{3}\right)_{2} \cdot 6 \mathrm{H}_{2} \mathrm{O}(35 \mathrm{mg}$, $0.12 \mathrm{mmol}),(R, R, R, R)-\mathbf{8}(58 \mathrm{mg}, 54 \mu \mathrm{mol})$ as dark green powder (62 $\mathrm{mg}, 88 \%$ yield for two steps) according to the procedure described for the synthesis of $(R, R, S, S)-\mathbf{2}$ : HRMS-APCI ${ }^{+}(m / z):\left[\mathrm{M}+\mathrm{H}-2\left(\mathrm{NO}_{3}\right)\right]^{+}$calcd for $\mathrm{C}_{64} \mathrm{H}_{73} \mathrm{Co}_{2} \mathrm{~F}_{2} \mathrm{~N}_{4} \mathrm{O}_{8}{ }^{+}, 1181.4055$; found, 1181.4055; anal. calcd for $\mathrm{C}_{64} \mathrm{H}_{72} \mathrm{Co}_{2} \mathrm{~F}_{2} \mathrm{~N}_{6} \mathrm{O}_{14}(\%)$ : C, 58.90; H, 5.56; N, 6.44; found: C, 59.23; H, 5.93; N, 5.06.

Representative procedure for the copolymerization of propylene oxide with phthalic anhydride (Table 1): A flamedried Schlenk tube was charged with the propylene oxide (1.4 mL, $20 \mathrm{mmol})$, phthalic anhydride $(296 \mathrm{mg}, 2.0 \mathrm{mmol})$, cobalt complex $(5.0 \mu \mathrm{mol}$ of Co center $)$, and co-catalyst $(5.0 \mu \mathrm{mol}[\mathrm{PO}] /[\mathrm{PA}] /[\mathrm{Co}] /[$ co-catalyst $]=4,000: 400: 1: 1)$ under argon. The reaction mixture was stirred at $30{ }^{\circ} \mathrm{C}$ for $1.0 \mathrm{~h}$. The polymerization mixture was diluted with $\mathrm{CH}_{2} \mathrm{Cl}_{2}$, and quenched with several drops of $\mathrm{MeOH} / 1 \mathrm{M} \mathrm{HCl}$ (50:50 vol \%). Phenanthrene as an internal standard was dissolved in the resulting mixture, and a small aliquot of the mixture was taken out and concentrated under reduced pressure. Then, the residue was analyzed by ${ }^{1} \mathrm{H}$ NMR spectroscopy and SEC to determine the conversion of PA, TOF, molecular weight, and molecular weight distribution.

The ${ }^{1} \mathrm{H}$ NMR spectra of the obtained PO/PA [15], CHO/PA [33], PO/CHDA [21], and PO/MA [15] copolymers were identical to those in the literatures.

Evaluation of regioregularity: The copolymerization of $(S)$-PO and PA was carried out under standard conditions using $(R, R, R, R)-1$. The reaction mixture was diluted with $\mathrm{CH}_{2} \mathrm{Cl}_{2}$ and quenched with several drops of $\mathrm{MeOH} / 1 \mathrm{M} \mathrm{HCl} \mathrm{(50:50} \mathrm{vol} \mathrm{\% ).}$ The resulting mixture was poured into an excess of $\mathrm{MeOH}$ to 
precipitate the copolymer. After the precipitation was repeated two more times, the precipitate was collected and dried under deduced pressure.

The obtained copolymer (ca. $150 \mathrm{mg}$ ) was dissolved in a mixture of $\mathrm{CH}_{2} \mathrm{Cl}_{2}(2.5 \mathrm{~mL})$ and $\mathrm{MeOH}(7.5 \mathrm{~mL})$, and $\mathrm{NaOH}$ $(100 \mathrm{mg})$ was added. After stirring at $60^{\circ} \mathrm{C}$ for $25 \mathrm{~h}$, the resulting suspension was neutralized with $4 \mathrm{M} \mathrm{HCl}$ (in cyclopentyl methyl ether). The solvents were removed under reduced pressure and $\mathrm{Et}_{2} \mathrm{O}(5 \mathrm{~mL})$ was added to the resulting powder. After stirring for $10 \mathrm{~min}$, the slurry was filtrated off and the resulting filtrate was concentrated under reduced pressure to give propylene glycol.

A flame-dried flask was charged with the obtained propylene glycol (26 mg, $0.34 \mathrm{mmol})$, 4-(dimethylamino)pyridine ( $8 \mathrm{mg}$, $0.07 \mathrm{mmol})$, trimethylamine $(70 \mu \mathrm{L}, 0.7 \mathrm{mmol})$, and $\mathrm{CH}_{2} \mathrm{Cl}_{2}$ ( $3.4 \mathrm{~mL})$. Benzoyl chloride $(39 \mu \mathrm{L}, 0.34 \mathrm{mmol})$ was added dropwise to the solution with stirring. After stirring at room temperature for $25 \mathrm{~min}$, the reaction mixture was poured into water and extracted with $\mathrm{CH}_{2} \mathrm{Cl}_{2}$. The organic layer was washed with $1 \mathrm{M} \mathrm{HCl}$ and brine and concentrated under reduced pressure. The resulting crude product was purified by the recycling preparative HPLC to give 2-hydroxypropyl benzoate [43]. The ee of the benzoate was determined by HPLC analysis using a DAICEL CHIRALCEL ${ }^{\circledR}$ IA-3 column $\left[t_{\mathrm{R}}=12.65 \mathrm{~min}\right.$ for the $(S)$-isomer and $14.50 \mathrm{~min}$ for the $(R)$-isomer (flow rate: $1.0 \mathrm{~mL}$; eluent: hexane/iPrOH 95:5)].

\section{Supporting Information}

\section{Supporting Information File 1 \\ NMR spectra of new compounds. \\ [https://www.beilstein-journals.org/bjoc/content/ supplementary/1860-5397-14-255-S1.pdf]}

\section{Acknowledgements}

This work was partially supported by MEXT KAKENHI Grant Number 16K05788.

\section{ORCID ${ }^{\circledR}$ iDs}

Koji Nakano - https://orcid.org/0000-0003-4166-7074

\section{References}

1. Hillmyer, M. A.; Tolman, W. B. Acc. Chem. Res. 2014, 47, 2390-2396. doi:10.1021/ar500121d

2. Coulembier, O.; Degée, P.; Hedrick, J. L.; Dubois, P. Prog. Polym. Sci. 2006, 31, 723-747. doi:10.1016/j.progpolymsci.2006.08.004

3. Gigli, M.; Fabbri, M.; Lotti, N.; Gamberini, R.; Rimini, B.; Munari, A. Eur. Polym. J. 2016, 75, 431-460. doi:10.1016/j.eurpolymj.2016.01.016
4. Albertsson, A.-C.; Varma, I. K. Aliphatic Polyesters: Synthesis, Properties and Applications. Degradable Aliphatic Polyesters; Springer: Berlin, Heidelberg, 2002; pp 1-40.

5. Albertsson, A.-C.; Varma, I. K. Biomacromolecules 2003, 4, 1466-1486. doi:10.1021/bm034247a

6. Dutta, S.; Hung, W.-C.; Huang, B.-H.; Lin, C.-C. Recent Developments in Metal-Catalyzed Ring-Opening Polymerization of Lactides and Glycolides: Preparation of Polylactides, Polyglycolide, and Poly(lactide-co-glycolide). In Synthetic Biodegradable Polymers; Rieger, B.; Künkel, A.; Coates, G. W.; Reichardt, R.; Dinjus, E.; Zevaco, T. A., Eds.; Springer: Berlin Heidelberg, 2012; pp 219-283.

7. Lecomte, P.; Jérôme, C. Recent Developments in Ring-Opening Polymerization of Lactones. In Synthetic Biodegradable Polymers; Rieger, B.; Künkel, A.; Coates, G. W.; Reichardt, R.; Dinjus, E.; Zevaco, T. A., Eds.; Springer: Berlin, Heidelberg, 2012; pp 173-217.

8. Lou, X.; Detrembleur, C.; Jérôme, R. Macromol. Rapid Commun. 2003 , 24, 161-172. doi:10.1002/marc.200390029

9. Thomas, C. M. Chem. Soc. Rev. 2010, 39, 165-173. doi:10.1039/b810065a

10. Stridsberg, K. M.; Ryner, M.; Albertsson, A.-C. Controlled Ring-Opening Polymerization: Polymers with designed Macromolecular Architecture. Degradable Aliphatic Polyesters; Springer: Berlin, Heidelberg, 2002; pp 41-65.

11. Paul, S.; Zhu, Y.; Romain, C.; Brooks, R.; Saini, P. K.; Williams, C. K. Chem. Commun. 2015, 51, 6459-6479. doi:10.1039/c4cc10113h

12. Longo, J. M.; Sanford, M. J.; Coates, G. W. Chem. Rev. 2016, 116, 15167-15197. doi:10.1021/acs.chemrev.6b00553

13. Fischer, R. F. J. Polym. Sci. 1960, 44, 155-172. doi:10.1002/pol.1960.1204414314

14. Jeske, R. C.; DiCiccio, A. M.; Coates, G. W. J. Am. Chem. Soc. 2007, 129, 11330-11331. doi:10.1021/ja0737568

15. DiCiccio, A. M.; Longo, J. M.; Rodríguez-Calero, G. G.; Coates, G. W. J. Am. Chem. Soc. 2016, 138, 7107-7113. doi:10.1021/jacs.6b03113

16. Van Zee, N. J.; Sanford, M. J.; Coates, G. W. J. Am. Chem. Soc. 2016, 138, 2755-2761. doi:10.1021/jacs.5b12888

17. Robert, C.; de Montigny, F.; Thomas, C. M. Nat. Commun. 2011, 2 , No. 586. doi:10.1038/ncomms 1596

18. DiCiccio, A. M.; Coates, G. W. J. Am. Chem. Soc. 2011, 133, 10724-10727. doi:10.1021/ja203520p

19. Hosseini Nejad, E.; van Melis, C. G. W.; Vermeer, T. J.; Koning, C. E.; Duchateau, R. Macromolecules 2012, 45, 1770-1776. doi:10.1021/ma2025804

20. Jeon, J. Y.; Eo, S. C.; Varghese, J. K.; Lee, B. Y. Beilstein J. Org. Chem. 2014, 10, 1787-1795. doi:10.3762/bjoc.10.187

21. Darensbourg, D. J.; Poland, R. R.; Escobedo, C. Macromolecules 2012, 45, 2242-2248. doi:10.1021/ma2026385

22. Sanford, M. J.; Van Zee, N. J.; Coates, G. W. Chem. Sci. 2018, 9 , 134-142. doi:10.1039/c7sc03643d

23. Winkler, M.; Romain, C.; Meier, M. A. R.; Williams, C. K. Green Chem. 2015, 17, 300-306. doi:10.1039/c4gc01353k

24. Van Zee, N. J.; Coates, G. W. Angew. Chem., Int. Ed. 2015, 54, 2665-2668. doi:10.1002/anie.201410641

25. Duan, Z.; Wang, X.; Gao, Q.; Zhang, L.; Liu, B.; Kim, I. J. Polym. Sci., Part A: Polym. Chem. 2014, 52, 789-795. doi:10.1002/pola.27057

26. Fournier, L.; Robert, C.; Pourchet, S.; Gonzalez, A.; Williams, L.; Prunet, J.; Thomas, C. M. Polym. Chem. 2016, 7, 3700-3704. doi:10.1039/c6py00664g

27. Matsunaga, S.; Shibasaki, M. Chem. Commun. 2014, 50, 1044-1057. doi:10.1039/c3cc47587e 
28. Park, J.; Hong, S. Chem. Soc. Rev. 2012, 41, 6931-6943. doi:10.1039/c2cs35129c

29. Delferro, M.; Marks, T. J. Chem. Rev. 2011, 111, 2450-2485. doi:10.1021/cr1003634

30. Matsunaga, S.; Shibasaki, M. Bull. Chem. Soc. Jpn. 2008, 81, 60-75. doi:10.1246/bcsj.81.60

31. Liu, J.; Bao, Y.-Y.; Liu, Y.; Ren, W.-M.; Lu, X.-B. Polym. Chem. 2013, 4, 1439-1444. doi:10.1039/c2py20842c

32. Garden, J. A.; Saini, P. K.; Williams, C. K. J. Am. Chem. Soc. 2015, 137, 15078-15081. doi:10.1021/jacs.5b09913

33. Zhu, Y.; Romain, C.; Williams, C. K. J. Am. Chem. Soc. 2015, 137, 12179-12182. doi:10.1021/jacs.5b04541

34. Yu, C.-Y.; Chuang, H.-J.; Ko, B.-T. Catal. Sci. Technol. 2016, 6, 1779-1791. doi:10.1039/c5cy01290b

35. Wu, L.-y.; Fan, D.-d.; Lü, X.-q.; Lu, R. Chin. J. Polym. Sci. 2014, 32, 768-777. doi:10.1007/s10118-014-1425-X

36. Saini, P. K.; Romain, C.; Zhu, Y.; Williams, C. K. Polym. Chem. 2014, 5, 6068-6075. doi:10.1039/c4py00748d

37. Thevenon, A.; Garden, J. A.; White, A. J. P.; Williams, C. K. Inorg. Chem. 2015, 54, 11906-11915. doi:10.1021/acs.inorgchem.5b02233

38. Zhu, L.; Liu, D.; Wu, L.; Feng, W.; Zhang, X.; Wu, J.; Fan, D.; Lü, X.; Lu, R.; Shi, Q. Inorg. Chem. Commun. 2013, 37, 182-185. doi:10.1016/j.inoche.2013.09.059

39. Liu, D.-F.; Wu, L.-Y.; Feng, W.-X.; Zhang, X.-M.; Wu, J.; Zhu, L.-Q.; Fan, D.-D.; Lü, X.-Q.; Shi, Q. J. Mol. Catal. A: Chem. 2014, 382, 136-145. doi:10.1016/j.molcata.2013.11.002

40. Hiranoi, Y.; Hatanaka, M.; Nakano, K. J. Polym. Sci., Part A: Polym. Chem. 2017, 55, 2150-2159. doi:10.1002/pola.28590

41. Previously, Lee and co-workers have reported by far the highest TOF $(\approx 1,900 \mathrm{~h}-1$ ) for the PO/PA copolymerization by using the cobalt-salen complex with ammonium tethers [20].

42. Cohen, C. T.; Chu, T.; Coates, G. W. J. Am. Chem. Soc. 2005, 127, 10869-10878. doi:10.1021/ja051744I

43. Liu, H.-X.; Dang, Y.-Q.; Yuan, Y.-F.; Xu, Z.-F.; Qiu, S.-X.; Tan, H.-B. Org. Lett. 2016, 18, 5584-5587. doi:10.1021/acs.orglett.6b02818

\section{License and Terms}

This is an Open Access article under the terms of the Creative Commons Attribution License (http://creativecommons.org/licenses/by/4.0). Please note that the reuse, redistribution and reproduction in particular requires that the authors and source are credited.

The license is subject to the Beilstein Journal of Organic Chemistry terms and conditions: (https://www.beilstein-journals.org/bjoc)

The definitive version of this article is the electronic one which can be found at: $\underline{\text { doi:10.3762/bjoc. } 14.255}$ 